\title{
Família e doença mental: a difícil convivência com a diferença*
}

\author{
FAMILY AND MENTAL DISEASE: THE HARD LIVING WITH THE DIFFERENCES
}

FAMILIA Y ENFERMEDAD MENTAL: LA DIFÍCIL CONVIVENCIA CON LA DIFERENCIA

\author{
Luciana de Almeida Colvero', Cilene Aparecida Costardi Ide ${ }^{2}$, Marli Alves Rolim ${ }^{3}$
}

\begin{abstract}
RESUMO
Este estudo partiu de reflexões acerca dos movimentos da reforma da assistência psiquiátrica e o processo de desinstitucionalização. Teve como objetivo identificar as representações sociais construídas por familiares acerca do fenômeno saúdedoença mental. Adotou-se o referencial das

representações sociais na perspectiva dos pressupostos de Moscovici. Foram entrevistados oito familiares de portadores de transtorno mental. Identificou-se que os familiares explicitam sua não aceitação daquele que se mostra diferente, como núcleo de suas representações sociais. Apontamos para a importância dos profissionais de saúde mental considerarem, em suas intervenções, o saber produzido pelos familiares.
\end{abstract}

\section{PALAVRAS-CHAVE \\ Familia. \\ Saude mental. \\ Transtornos mentais. \\ Enfermagem psiquiatrica.}

\begin{abstract}
This study started from the reflections on the Psychiatric Care Reform and the

desinstitutionalization process. The goal of this study is to identify the social representations built by the patients' relatives on the mental healthdisease phenomenon. For analysis we have adopted the social representation referential through the Moscovici perspective. Eight relatives of the patients were interviewed. We have identified the mentioned relatives, considering those who are really different, as the center of their social representations. We have point out the importance of the mental health professionals to give careful considerations on their interventions, regarding to the knowledge emerged from the report of the patients, relatives.
\end{abstract}

\section{KEYWORDS}

Family.

Mental health.

Mental disorders.

Psychiatric nursing.

\section{RESUMEN}

Este estudio fue realizado a partir de reflexiones a cerca de los movimientos de la reforma de la asistencia psiquiátrica y el proceso de desinstitucionalización del enfermo mental en el país. Tuvo como objetivo identificar las representa-ciones sociales construidas por familiares respecto al fenómeno saludenfermedad mental. Se adoptó como referencial las representa-ciones sociales en la perspectiva de Moscovici. Fueron entrevistados ocho familiares de portadores de enfermedad mental. El estudio permitió identificar que los familiares manifiestan su noaceptación de aquel que se muestra diferente, como núcleo de sus representaciones sociales. Resaltamos la importancia de que los profesionales de salud mental consideren en sus intervenciones, el saber producido por los familiares.

\section{PALABRAS CLAVE}

Familia.

Salud Mental.

Transtornos mentales.

Enfermería psiquiátrica.
* Trabalho apresentado no Congresso Internacional "Pesquisando a Família", realizado em Florianópolis, de 24 a 26 de abril de 2002. Parte da Tese de Doutorado intitulada: Desafios da família na convivência com o doente mental: cotidiano conturbado, Escola de Enfermagem da USP(EEUSP), 2002.

1 Enfermeira. Professora Doutora do Departamento de Enfermagem Materno -Infantil e Psiquiátrica da EEUSP. Orientanda. lucix@usp.br

2 Enfermeira. Professora Titular do Departamento de Enfermagem MédicoCirúrgica da EEUSP. Orientadora. cilenecostardi@ig.com.br

3 Enfermeira. Professora Doutora do Departamento de Enfermagem Materno-Infantil e Psiquiátrica da EEUSP. Co-Orientadora. minie@usp.br 
Luciana de Almeida Colvero Cilene Ap. Costardi Ide Marli Alves Rolim

\section{INTRODUÇÃO}

Trabalhar o tema família e doença mental decorre de nosso interesse de compreender como é a vida cotidiana do familiar de portadores de transtorno mental grave, sua convivência com a doença e ou doente mental e identificar as representações por eles construídas a respeito do fenômeno saúdedoença mental, face às transformações paradigmáticas que estão a orientar este campo da saúde mental.

Diante das marcas de uma cultura globalizada inscrita no campo simbólico e na construção dos saberes sociais, identificamos a família enquanto um grupo que constitui um campo de relações entre pessoas que compartilham significados de suas experiências existenciais. Este grupo atravessa os tempos passando por inúmeras transformações e críticas, sem afastar-se, ao menos em tese, da responsabilidade e das exigências dos papéis socialmente atribuídos a ela de procriar e criar filhos saudáveis e preparados para assumir o mercado profissional e a vida em coletividade.

Até bem pouco tempo, a assistência ao doente mental apresentava-se centrada nos hospitais psiquiátricos, locais da prática e do saber médico, cujo modelo de atenção restringia-se à internação e medicalização dos sintomas demonstrados pelo doente mental, excluindo-o dos vínculos, das interações, de tudo o que se configura como elemento e produto de seu conhecimento.

No modelo de atenção atual, a política assistencial vigente preconiza a diminuição da oferta de leitos hospitalares e a criação de serviços substitutivos de atenção à saúde mental deslocando, assim, o seguimento e evolução dos tratamentos para o interstício das dinâmicas familiares mobilizadas pela inclusão dos portadores de transtorno mental.

De concreto, sabemos que não há serviços na comunidade suficientes e disponíveis que consigam dar conta da demanda de portadores de transtorno mental e seus familiares com efetividade. Sabemos, também, que a ocorrência de uma doença grave e de longa duração, como a doença mental ,ativa uma série de respostas nas pessoas de seu grupo social, especialmente, entre aquelas do convívio familiar.
Em face destas evidências, passamos a nos interrogar se a assistência prestada aos familiares pelos equipamentos de saúde mental estava indo de encontro às suas reais necessidades. Por exemplo - Por que os grupos de atendimento de familiares, depois de determinado tempo, ficam esvaziados? O que dificulta a aderência dos familiares dos portadores de transtorno mental aos tratamentos oferecidos pelos serviços? Não satisfazem as respostas que apontam os familiares como sujeitos resistentes às orientações e, por conseguinte, considerá-los como "maus familiares", culpando-os pela dificuldade de atingirem as metas institucionais.

O familiar, ainda, apresenta-se aos serviços simplesmente como "informante" das alterações apresentadas pelo doente mental, e deve, por conseguinte, seguir passivamente as prescrições dadas pelo tratamento oferecido. Portanto, acolher suas demandas, considerando as vivências inerentes a esse convívio, promovendo o suporte possível para as solicitações manifestas pelo grupo familiar continuam a ser o maior projeto de superação.

Afinal, o "fato novo" com o qual a família está a se deparar é que o tratamento de seu familiar portador de transtorno mental não está mais centrado no hospital psiquiátrico. Nos quadros agudos recomenda-se que a internação seja de curta permanência, e a continuidade do tratamento realizada nos equipamentos extra-hospitalares; por conseguinte, o doente mental retornará à casa, à família (quando ela existe) e à comunidade.

A assistência prestada aos portadores nos mostra que os familiares que procuram a ajuda e suporte dos serviços de saúde mental e de seus profissionais, apresentam demandas das mais variadas ordens, dentre elas, a dificuldade para lidarem com as situações de crise vividas, com os conflitos familiares emergentes, com a culpa, com o pessimismo por não conseguir ver uma saída aos problemas enfrentados, pelo isolamento social a que ficam sujeitos, pelas dificuldades materiais da vida cotidiana, pelas complexidades do relacionamento com o doente mental, sua expectativa frustrada de cura, bem como pelo desconhecimento da doença propriamente dita, para assinalarmos, algumas dentre tantas outras insatisfações. 
Face a este complexo cotidiano, acreditamos que as ações dirigidas à família de indivíduos portadores de transtorno mental grave devam estruturar-se de maneira a favorecer e potencializar a relação familiar/ profissional/serviço. Compreendendo o familiar como um parceiro singular e fundamental para o cuidado dispensado ao doente mental.

O sentido desta parceria está orientado para a ação de cuidar deste familiar; há, portanto, que se incluir este sujeito como alguém que tem muito a dizer, especialmente quanto a seu próprio sofrimento psíquico e o quanto este mobiliza sua vida. Para isso, partimos do entendimento de que é necessário considerar sua demanda, para além da objetividade manifesta em suas queixas, geralmente centradas no sintoma do outro, do seu familiar portador de transtorno mental.

Nesta perspectiva, identificamos que estes familiares possuem um saber, saber este constituído na relação com o doente mental e com os profissionais, que atravessa todas as suas queixas e pedidos de ajuda. Este saber, construído no senso comum, consiste em uma operação que dá um sentido às metáforas e imagens que lhes são oferecidas pela história social de seu tempo sobre o processo saúdedoença mental e convívio familiar, e por conseguinte, precisa ser identificado.

\section{CONTEXTUALIZANDO O CAMPO DASAÚDE MENTALE A EXPERIÊNCIA FAMILIAR NO CUIDAR DESINSTITUCIONALIZADO}

Desde o advento da medicalização e institucionalização das ações sobre a doença mental, podemos associar a representação da loucura construída sobre o modelo de exclusão social que "refere-se ao isolamento de indivíduos de conduta desviante ou considerados indesejáveis pela comunidade"(1).

Estas representações da loucura estão presentes em vários estudos históricos e, de acordo com Resende ${ }^{(2)}$, a exclusão nos chamados hospícios dava-se ou por motivos de eficácia do tratamento, ou porque suas causas estavam associadas às relações familiares, ou ainda, porque o doente mental representava perigo ao grupo social, dada a dificuldade de "controlá-lo".

Por intermédio da história da psiquiatria, é possível identificarmos as atitudes dela em relação à família do portador de agravo mental. Evidenciamos que se a família, em algum momento, retirou-se da cena do cuidado de seu familiar doente mental, em outros, ela foi excluída por ser considerada como "nociva ao tratamento", isto é, como causadora da doença, pois atrapalhava o tratamento proposto. Outras vezes, ela delegou esse cuidado pelo desconhecimento de não saber como agir frente a certas manifestações do doente, pela sobrecarga física e emocional que o sujeito doente acarreta a seus membros ${ }^{(3-5)}$.

O pós-guerra-mundial pode ser identificado como um "divisor de águas" entre dois grandes movimentos que assinalaram a evolução dos modelos da assistência psiquiátrica. Segundo a literatura, o século XIX é marcado pelo movimento da medicalização e "institucionalização das práticas terapêuticas;o doente mental deixa sua comunidade para ser internado e tratado em grandes asilos". Já no período pós-guerra, na segunda metade do século XX, assistiuse a um movimento contrário, orientado pelo "esforço da desinstitucionalização: o doente mental deve deixar os hospitais e retornar à sua comunidade" ${ }^{n-8}$.

No Brasil, na atualidade, bem como em vários países do mundo, vêm ocorrendo mudanças significativas nas políticas que norteiam a assistência ao portador de transtorno mental, cujo sentido geral objetiva a transformação das relações da sociedade com estas pessoas. Os movimentos de Reforma da Assistência Psiquiátrica estão marcados pelo processo da desinstitucionalização.

Na perspectiva que nos interessa destacar neste estudo, o conceito de desinstitucionalização contribuiu para os movimentos da Reforma da Assistência Psiquiátrica no país a partir da década de 80 , sendo entendido como a desconstrução da cultura manicomial no contexto da perspectiva das idéias de Basaglia. Esta Reforma emerge no bojo de uma ampla discussão a respeito de recentes práticas terapêuticas, práticas estas sustentadas por uma nova ética relativa ao cuidado de pessoas que sofrem de transtornos mentais graves $^{(9)}$.

Sob o ponto de vista da desinstitucionalização, como um paradigma emergente, o campo da saúde mental amplia-se face à existência de um novo e complexo objeto: o
Família e doença mental: a difícil convivência com a diferença 
Luciana de Almeida Colvero Cilene Ap. Costardi Ide Marli Alves Rolim sujeito e seu transtorno mental em relação com o corpo social. Este modelo constitui-se como tal pela permanente tensão com o paradigma dominante da psiquiatria, cujo objeto restringe-se à doença mental e à periculosidade social que o doente mental representa $^{(10-11)}$.

Portanto, se outrora coube ao hospício legitimar suas ações sobre a loucura, separando o portador de transtorno mental da família na crença de que esta modalidade de tratamento reorganizaria o contato entre o doente, a família e sociedade. Hoje, estamos diante de uma nova lógica a orientar a atenção ao doente mental - a lógica da inclusão entendendo-se este sujeito não constituído apenas de um aparelho psíquico que, eventualmente, necessite de diagnóstico e tratamento. Implica muito mais. A doença mental deve ser compreendida como um fenômeno complexo e histórico, atravessado pelas dimensões psicossociais que determinam o processo saúde-doença mental.

Conforme demonstra os dados da literatura consultada para este trabalho, esta movimentação no cenário das políticas públicas repercutiu no campo assistencial da saúde mental no Brasil. A partir da década de 80 , evidenciamos os reflexos da tendência observada na Europa e Estados Unidos, após a segunda Guerra Mundial. Cabe destacar, também, a Declaração de Caracas em 1990, como marco de fundamental importância para os processos da Reforma da Assistência Psiquiátrica na região das Américas ${ }^{(12)}$.

Em nosso país, o processo da Reforma da Assistência Psiquiátrica vem apresentando avanços nos últimos trinta anos; todavia, embora haja inúmeras iniciativas bem sucedidas no campo da saúde mental, a cultura asilar ainda está muito presente em nosso cotidiano como o recurso assistencial de mais fácil acesso à população.

Diversas iniciativas governamentais ,e nãogovernamentais, de experiências inovadoras que estão presentes em várias cidades do país, em diferentes Estados, podem ser identificadas. Experiências que cada vez mais privilegiam a criação de serviços descentralizados, estruturados em torno de recursos locais, próximos da realidade vivida pela comunidade; dentre estes, encontramos os hospitais-dia, os centros de atenção psicossocial, moradias assistidas e leitos em hospitais gerais.
Frente ao exposto, ao partirmos da ampliação do campo da saúde mental, de seus modelos de intervenções, espaços da prática assistencial e das relações deste campo com a família do doente mental, consideramos que esta vivencia as propostas e os desdobra-mentos do movimento da Reforma da Assistência Psiquiátrica em curso no país. Assim, nos interrogamos: como esses familiares estarão representando o binômio saúde-doença mental nesse contexto. Como estas transformações estarão repercutindo na vida desses familiares?

$\mathrm{Na}$ perspectiva de abordagem da Reabilitação Psicossocial,

a doença não reside, isolada $\mathrm{e}$ culpabilizante, dentro do sujeito, mas no território virtual que é a interação entre os membros da família(13);

o que não significa que a família deva ocupar o lugar de culpada ou vítima. Nesta abordagem desinstitucionalizante, a família deverá ser incluída na condição de protagonista do cuidado reabilitador.

Assim, evidenciamos que o retorno do doente mental à família e à comunidade é polêmico e permeado por contradições; dentre estas, é oportuno reiterarmos a carência de serviços extra-hospitalares na comunidade, a descontinuidade dos programas de reinserção social do doente mental e a desconsideração dos desgastes a que ficam sujeitos os familiares. São aspectos que vêm sendo levantados por autores em uma perspectiva crítica ao processo da desinstitucionalização no Brasil e em outros países do ocidente ${ }^{(1,14-17)}$.

Segundo a literatura, uma vez que entendemos ser a psiquiatria uma prática social e multifacetada que não restringe o objeto de suas ações na doença mental, mas sim, na "experiência do sofrimento psíquico de sujeitos inseridos em contextos socioculturais mutantes", há que se assumir uma posição crítica permanente no sentido de evitarmos "uma burocratização das práticas e a fetichização da teoria"(18).

Sgambati(19), na década de 80 , analisa a relação entre as re-internações do doente mental em hospital psiquiátrico e a rejeição familiar. Enfatiza que 
o aumento das altas hospitalares não tem sido acompanhado pela criação de serviços assistenciais na comunidade para absorver esse contingente de doentes, e não tem sido avaliado se suas famílias estão preparadas para assumir esse encargo ${ }^{(19)}$.

Assim, na prática, assistimos aos processos de desospitalização e desassistência das pessoas que sofrem psiquicamente. Fato que vem dificultando em muito a inclusão do familiar como protagonista nas estratégias de cuidado e em um suposto papel de parceria com os trabalhadores nos diversos projetos, em diferentes equipamentos de atenção à saúde mental.

Diante dos quadros graves de sofrimento mental e de longa duração, como a esquizofrenia por exemplo, encontramos familiares pessimistas quanto à possibilidade de melhora do familiar doente mental. Para muitos, são tantos os fracassos, recaídas, abandonos de tratamento, que é comum encontrarmos familiares desmotivados, resistentes e temerosos frente a qualquer proposta de mudança, vinda dos trabalhadores e dos serviços.

Particularmente para fins deste trabalho, detivemo-nos em estudos científicos que abordam o impacto e a sobrecarga a que ficam sujeitos os familiares envolvidos na convivência com as pessoas que apresentam um transtorno mental grave ${ }^{(20-23)}$ por não termos como objetivos da pesquisa a análise das dinâmicas das famílias envolvidas, no que diz respeito à gênese do sofrimento psíquico. $\mathrm{O}$ foco, aqui, se volta à compreensão das repercussões da re-inclusão do doente mental no cotidiano de vida de seus familiares.

Portanto, por entendermos a forte influência dos movimentos descritos em nossa prática atual com os familiares de portadores de transtorno mental e que, por força do modelo, precisam absorver responsa-bilidades de um cuidar que se torna leigo e deslocado para o próprio ambiente doméstico, apesar de toda a complexidade inerente ao quadro apresentado pelo familiar doente mental, buscamos apreender as represen-tações de familiares a respeito do processo saúde-doença mental, focalizando a convivência com o doente mental.

\section{TRAJETÓRIA METODOLÓGICA}

O presente estudo foi desenvolvido em um Centro de Atenção Psicossocial (CAPS), da cidade de São Paulo, serviço da Secretaria de Estado da Saúde, que ainda não havia sido municipalizado no momento da coleta dos dados. Este equipamento é composto por um Hospital Dia (HD), para atendimento de pacientes com transtornos mentais graves e um Ambulatório de Saúde Mental que dentre outras atividades procura dar seguimento aos egressos do HD.

Aceitaram participar da pesquisa oito familiares, escolhidos aleatoriamente, todos do sexo feminino, mães e irmãs de portadores de transtorno mental atendidos no referido equipamento. A estas pessoas foi oferecida a possibilidade da entrevista ser realizada no local que eles escolhessem, em apenas um caso a entrevista foi desenvolvida no domicílio, os demais sete colaboradores optaram para que a entrevista se realizasse no próprio CAPS.

No horário e local da entrevista foi-lhes entregue o "Termo de Consentimento Livre e Esclarecido", aprovado pelo Comitê de Pesquisa da Escola de Enfermagem da USP, salientando que todas as informações prestadas nesse momento visaram assegurar a liberdade para a escolha dos sujeitos de participar ou não da pesquisa e sua desistência não acarretaria em ônus para os depoentes e portadores.

Com base na teoria das representações sociais segundo a perspectiva de Moscovici(24), e pelo recurso da técnica de análise de discurso ${ }^{(25)}$, procurou-se estudar a forma como o grupo de familiares constrói um conjunto de saberes acerca do fenômeno estudado. A metodologia qualitativa possibilitou ir de encontro à vivência cotidiana dos sujeitos estudados, os familiares de portadores de transtorno mental.

Por meio de seus relatos, podemos apreender o conhecimento gerado pelo senso comum, ou seja, um "saber social"(26) que é construído pelo envolvimento das dimensões cognitivas, simbólicas e imaginativas colhidos nas mais variadas fontes e experiências individual e grupal e que teriam, entretanto, uma singularidade decorrente da estrutura dessas famílias e do substrato social que lhes dá sustentação. Temos a compreensão de que estes fatores constituem em si campo estruturado e estruturante de significação às representações que os sujeitos construíram e estão a construir a respeito do objeto da pesquisa, o binômio saúde - doença mental.
Família e doença mental: a difícil convivência com a diferença 
Luciana de Almeida Colvero Cilene Ap. Costardi Ide Marli Alves Rolim

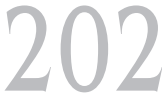

Rev Esc Enferm USP 2004; 38(2):197-205.

\section{RESULTADOS E DISCUSSÕES}

Os familiares inicialmente verbalizam o impacto que a doença mental representou em suas vidas, especialmente pelos momentos de crise, bem como seus reflexos no grupo familiar. Mediante uma atitude cognitiva e afetiva procuravam explicar e classificar, segundo um conhecimento já acumulado, o que estava se passando com seu irmão ou filho portador de transtorno mental.

Dos depoimentos apreendemos que, depois da primeira crise diagnosticada, os familiares foram capazes de nomear a doença mental de seu filho ou irmão como um "comportamento diferente", perceptível desde a infância e ou adolescência, um período da vida antes do aparecimento da doença mental, mas que foi sendo atenuado, suportado na tentativa de relativizar sua gravidade.

Diante dos sintomas da esquizofrenia, que é o diagnóstico médico de sete dos oito usuários que tiveram seus familiares entrevistados para este estudo, todas as depoentes manifestaram extrema dificuldade de lidar com alguns comportamentos, dentre eles, as alucinações, delírios, distúrbios do pensamento, comportamento de auto e heteroagressividade e, especialmente, com os chamados sintomas negativos que são aqueles relacionados a uma apatia marcante, pobreza de discurso e embotamento ou incongruência de respostas emocionais ${ }^{(27-28)}$.

Nestes momentos, selecionaram determinados elementos do comportamento daquele, identificando o que é diferente, estranho e incomoda, na tentativa de encontrarem uma resposta que explique e justifique toda a mudança de comportamento identificada assim buscam entendimento do que venha ser "a doença mental".

Os depoentes destacam também que a convivência com o familiar doente mental é marcada por um sentimento de insegurança e desconforto diante da imprevisibilidade de suas ações, convivem com a expectativa de que algo súbito possa acontecer a qualquer momento.

Face a estas evidências, os familiares assumem, sentirem-se sobrecarregadas com a relação de extrema dependência material e afetiva e falta de iniciativa apresentada por seu filho e irmão. Além disso, o quadro apresentado pelo familiar doente mental não se altera, apesar do tratamento recebido, enfim um esforço realizado por elas que não é reconhecido nem retribuído é desprovido de sentido.

Assim, estes familiares ao se apropriarem de um "corpus teórico-técnico", o diagnóstico psiquiátrico, vão retirar elementos de um conjunto de idéias em circulação a respeito do binômio saúde-doença mental que farão sentido ao universo do senso comum.

$\mathrm{O}$ intuito desse processo de assimilação representacional parece ser a tentativa de normalizar o estranho, assimilar seu caráter desviante, relativizando as expressões dessas condutas. Para esse processo, buscando preservar a coerência com o sistema dos valores próprios ao grupo, os familiares selecionaram os elementos que estejam de acordo com seus critérios culturais e que por sua vez, expressam condições desiguais de acesso às informações ${ }^{(29)}$.

Nas unidades dos discursos, este estranho é apresentado como aquele que faz coisas diferentes que as pessoas normais não costumam fazer, por exemplo não se comportam de acordo com as normas sociais e familiares; não são responsáveis; não avisam onde vão; faltam ao trabalho ou não querem trabalhar; não cuidam de suas coisas e de si mesmo; muitas vezes envolvem - se com atividades ilícitas; expressam idéias que estão fora da realidade; isolam-se e não interagem adequadamente com as pessoas que os cercam.

Vejamos alguns trechos dos discursos:

__ (...) No começo era difícil, ele fazia coisa assim diferente da gente, não se comportava como uma pessoa normal (...)

__ (...)Quando começou a primeira crise dele eu não sabia que era essa doença, ele sumiu de casa e a gente achou que era uma falta de responsabilidade dele (...)

(...) Eu sei que ele é uma pessoa doente mental, não é uma pessoa comum (...) (...) $\mathrm{O}$ comportamento dele a gente poderia chamar assim de diferente, o abandono da escola, o envolvimento com as drogas $(. .$.

(...) ele sempre foi uma pessoa diferente, um menino arredio, nunca foi de brincar com os irmãos, sempre afastado, sempre solitário.

Esta estranheza diante do comportamento de seu familiar doente mental, identificada 
na convivência diária das depoentes, indica a compreensão de padrões de comportamento não aceitos por elas mesmas e, por conseguinte, passíveis de rejeição pelo grupo social.

Estes familiares demarcam, assim, essa diferença a partir daquilo que para eles aparece como estranho, não esperado e não compreensível no comportamento de seu familiar doente mental e o fazem fundamentados nos saberes historicamente acumulados e reiterados por meio de relações sociais. Saberes estes sintetizados em antinomias, muitas vezes, maniqueístas, do normal \& anormal, do bom \& mal, do certo \& errado, da saúde \& doença, do comum \& incomum; base racionalista do pensamento moderno.

A “diferença", identificada como uma palavra matriz, transpõe o imaginário “dando primeiramente um sentido ao real e em segundo lugar uma classificação cognitiva", apresenta-nos uma determinada realidade objetiva para em seguida, simbolizar uma representação social do fenômeno saúdedoença mental. Neste sentido, "a diferença" constitui-se em um

signo criador de trocas de motivações semânticas e formas verbais, solidificando os laços de reciprocidade e reforçando as redes de interações sociais( ${ }^{(24)}$.

A figura do outro estranho e diferente sempre representou interesse e, na literatura, podemos encontrar pronunciamentos em distintos contextos teóricos. Como podemos ver acerca da loucura em Foucaut ${ }^{(30)}$

não existe cultura que não seja sensível, na conduta e na linguagem dos homens, a certos fenômenos com relação aos quais a sociedade toma uma atitude particular: estes homens não são considerados nem completamente como doentes, nem completamente como criminosos, nem feiticeiros, nem inteiramente como pessoas normais. Há neles algo que fala da diferença e chama a diferenciação.

Segundo o estudo(31), que compara os paradigmas da modernidade e pós-modernidade, fazendo um paralelo à mitologia grega, refere-se que o deus Dionísio era um estranho ao mundo grego, à cultura grega. Por isso incomodava a religião do Olimpus praticada pela classe dirigente, incompatibilizando-se com os costumes helênicos de então. $\mathrm{O}$ autor afirma que a origem estrangeira de Dionísio e as reações a seu culto põem em destaque o medo à alteridade, o incômodo que nos causa o que é estranho. Não é possível nenhum sentimento de irmanação, de pertencimento, de co-participação para aquele que nos é profundamente diferente ${ }^{(31)}$.

Assim podemos evidenciar nas falas das depoentes:

- (...) me causa um desconforto estar dentro da sua casa com uma pessoa que é um estranho dentro da sua casa, eu não sei quem é essa pessoa, embora seja o meu irmão, eu não conheço a personalidade dele (...)

__ (...) a minha vida é muito triste porque, às vezes, eu não me conformo com a maneira dela ser, eu não admito, não aceito o jeito que ela é (...)

_ (...) atrapalha bastante a não aceitação do estado dele, quer dizer, os meus pais acham que nem tudo é sintoma da doença, que muita coisa é criancice, sem vergonhice (...)

Ao longo dos depoimentos, os familiares expressam os sentimentos mobilizados nessa convivência com alguém que eles afirmam desconhecer e ao atribuírem diferentes explicações ao comportamento apresentado pelo familiar doente mental, parecem estar procurando respostas para o que de fato, tem seu filho ou irmão, para uns é criancice, meio de vida, falta de responsabilidade, preguiça, para outros é problema da mente, do espírito.

Conforme os depoimentos que se seguem:

_ (...) eu acho que a gente sabe pouco sobre doença mental, é difícil de avaliar até onde é doença, até onde é comportamento, porque você não está vendo, ela não é uma doença aparente (...)

_ (...) a gente vê, assim uma pessoa normal, mas por dentro não é aquilo que a gente pensa, não sei explicar, não tem explicação para essa doença (...)

_ (...)eu nem sei explicar, os médicos daqui acham que essas vozes, que ele ouve é porque ele tem psicose. Os pastores falam que ele tem problema espiritual, eu acho que ele tem um problema de psicose, mas também acho que ele tem problema de espírito.

A doença mental ao mesmo tempo em que faz parte da vida cotidiana, é um fenômeno psicossocial pouco compreendido e aceito e, de certa maneira, temido por eles. Suas falas
Família e doença mental: a difícil convivência com a diferença 
Luciana de Almeida Colvero Cilene Ap. Costardi Ide Marli Alves Rolim apresentam julgamentos, pré-juízos, receios, dúvidas e fragilidades, "face ao que é implicitamente suposto ser um diferente incurável, um fenômeno incontrolável e imprevisível”(31).

A qualificação pelo diagnóstico psiquiátrico do quadro apresentado pelo familiar mobiliza um jogo significativo entre o conhecimento institucional (político, administrativo, profissional) e o conhecimento dos grupos sociais (família, comunidade) sobre o processo saúde-doença mental. Este jogo ocorre por meio da comunicação, como veículo que irá convertendo o doente mental nesse outro diferente, formando assim uma representação que terá o duplo papel "de tornar o estranho familiar e o invisível em perceptível"(29).

No entanto, nesta procura por entendimento, eles reiteram em diversos momentos a dificuldade de conviver com uma pessoa doente mental, como se nada afinal conseguisse efetivamente apaziguar seus corações e mentes, isto é, como se nenhuma resposta fizesse sentido, face às experiências singulares desses familiares com o familiar portador de transtorno mental.

\section{CONCLUSÕES}

Evidenciamos que os familiares deste estudo não explicam nem compreendem plenamente a doença mental de seu filho e irmão, é como se eles não conseguissem associar, por exemplo, os citados "comportamentos diferentes" a algo já conhecido por eles ou já vivenciado. É uma experiência que lhes escapa, entretanto, os sentimentos mobilizados na convivência diária despertamlhes os sentidos. Seus depoimentos são assim, marcados pela pluralidade de sentidos e significados que atestam a diversidade de maneiras de compreenderem e explicarem o binômio saúde-doença mental.

\section{REFERÊNCIAS}

(1) Lougon M. Desisntitucionalização da assistência psiquiátrica: uma perspectiva crítica. Physis: Rev Saúde Coletiva 1993; 3(2):137-64.

(2) Resende H. Política de saúde mental no Brasil: uma visão histórica. In: Tundis SA,Costa NR. organizadores. Cidadania e loucura: políticas de saúde mental no Brasil. Petrópolis: Vozes; 1987. p. 15-73.
A doença mental é representada pelos familiares pelo processo de objetivação do familiar doente mental como aquele que é - o diferente - que faz coisas que os outros, ditos normais, não fazem. Esse conceito vai se materializando por meio de repetidas comparações entre o tempo da saúde, quando seu filho e irmão trabalhavam estudavam e eram responsáveis...enfim, "um filho nota mil". Nessa convivência, o tempo da doença é identificado pelos aspectos negativos impostos pelos comportamentos que despertam o estranhamento e o desconforto.

Os sujeitos estudados efetuam um movimento dialético e contínuo de busca por uma referência, isto é, eles foram tecendo os laços dos saberes sociais assimilados, quando selecionaram os elementos explicativos a respeito do comportamento apresentado pelo familiar portador de transtorno mental que, de maneira geral, estão ancorados ora como um desvio de ordem moral, ora religiosa, ora social e ora orgânica.

Os familiares constróem representações do processo saúde-doença mental, caracterizadas pela diversidade, fluidez e ambigüidade. Fato este que nos pareceram, não favorecerem aos sujeitos pesquisados realizarem a operação de tornarem o conhecimento sobre o comportamento diferente do filho e irmão portador de transtorno mental em algo compreensível e assimilável para eles.

Portanto, quando nos remetemos aos princípios que orientam o processo da Reforma da Assistência Psiquiátrica, bem como às estratégias de integração re-inserção social do portador de transtorno mental na família e na comunidade necessitamos considerar as evidências apresentadas, relativas às experiências singulares desses familiares dadas na convivência com o portador de transtorno mental que estão a orientar os diferentes modos de representarem o binômio saúde-doença mental.

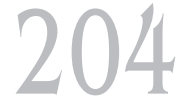

Rev Esc Enferm USP 2004; 38(2):197-205.
(3) Castel R. A ordem psiquiátrica: a idade de ouro do alienismo. Rio de Janeiro: Graal; 1978.

(4) Machado R. Danação da norma: medicina social e constituição da psiquiatria no Brasil. Rio de Janeiro: Graal; 1978. 
(5) Koga M. Convivência com a pessoa esquizofrênica: sobrecarga familiar. [dissertação] Ribeirão Preto(SP): Escola de Enfermagem de Ribeirão Preto/USP; 1997.

(6) Venâncio ATA. A construção social da pessoa e a psiquiatria: do alienismo à "nova psiquiatria”. Physis: Rev Saúde Coletiva 1993; 3(2): 117-35.

(7) Amarante PDC, organizador. Loucos pela vida: a trajetória da reforma psiquiátrica no Brasil. Rio de Janeiro: SDE/ENSP; 1995.

(8) Silva Filho JF, Figueiredo AC, CavalcantI MT. Apresentação. Cad IPUB 1996; 3.

(9) Pereira RC. Lugar de louco é no hospício?! um estudo sobre as representações sociais em torno da loucura no contexto da reforma psiquiátrica. In: Venâncio AT, Leal EM; Delgado GD. O campo da atenção psicossocial. Rio de Janeiro: Te Corá; 1997. p. 328-49.

(10) Kuhn TS. A estrutura das revoluções científicas. São Paulo: Perspectiva; 1996.

(11) Santos BS. Pela mão de Alice: o social e o político na pós-modernidade. São Paulo: Cortez; 1977. Cinco desafios à imaginação sociológica; $17-22$.

(12) Declaração de Caracas. In: Ministério da Saúde Legislação em Saúde Mental - 1990 - 2000. Brasília; 2000. p. 9-10. (Série E - Legislação em saúde, n. 4).

(13) Saraceno B. Libertando identidades da reabilitação psicossocial à cidadania possível. Belo Horizonte: Te Corá; 1999.

(14) Bandeira M, Lesage A, Morissette R. Desintitucionalização: importância da infra- estrutura comunitária de saúde mental. J Bras Psiquiatr 1994; 43(12):659-66.

(15) Bandeira M, Gelinas D, Lesage A. Desisntitucionalização: o programa de acompanhamento intensivo na comunidade. J Bras Psiquiatr 1998; 47(12):627-40.

(16) Lima LA, Teixeira JM. Assistência à saúde mental no Brasil: do mito de excesso de leitos psiquiátricos à realidade da falta de serviços alternativos de atendimento. J Bras Psiquiatr 1995; 44(2):71-6.

(17) Sadigursky D. Desisntitucionalização do doente mental: expectativas da família. [tese] Ribeirão Preto (SP): Escola de Enfermagem de Ribeirão Preto/USP; 1997.

(18) Bezerra JRB. A diversidade no campo psiquiátrico: pluralidade ou fragmentação. Cadernos IPUB 1999; 14:135-44.
(19) Sgambati ERV. Reinternação e rejeição familiar: um estudo com pacientes psiquiátricos. [dissertação] Ribeirão Preto (SP): Escola de Enfermagem de Ribeirão Preto/USP; 1983.

(20) Carmo DR. Contribuição ao estudo da integração na família de pacientes egressos de hospitais psiquiátricos. [dissertação]Ribeirão Preto(SP): Escola de Enfermagem de Ribeirão Preto/USP; 1981.

(21) Platt S. Measuring the burden of psychiatry illness on the family: in evaluation of same rating scales. Psychol Med 1985; 15 (2):383-93

(22) Ortiz MA, Tostes VMCS. Uma experiência com grupo de familiares no Hospital Dia. J Bras Psiquiatr 1992; 41(6):271-5.

(23) Melman J. Repensando o cuidado em relação aos familiares de pacientes com transtorno mental. [dissertação]São Paulo(SP): Faculdade de Medicina da USP; 1998.

(24) Moscovici S. A representação social da psicanálise. Rio de Janeiro: Zahar; 1978.

(25) Bardin L. Análise de conteúdo. Lisboa: Edição 70; 1994

(26) Guareschi PA, Jovchelovitch S. Textos em representações sociais. 2. ed. Petrópolis: Vozes; 1995. Introdução; p. 17-25.

(27) Louzã Neto MR, organizador. Psiquiatria básica. Porto Alegre: Artes Médicas; 1995.

(28) Organização Mundial da Saúde. CID-10: critérios diagnósticos para pesquisa. Porto Alegre: Artes Médicas; 1998.

(29) Nóbrega SM. Sobre a teoria das representações sociais In: Moreira ASP, Organizador. Representações sociais: teoria e prática. João Pessoa: Universitária; 2001. p. 55-87

(30) Rezende ALM. A sedução dos mitos da saúde e doença na telenovela. [tese]São Paulo(SP): Faculdade de Educação da USP; 1993.

(31) Morant N, Rose D. Loucura, multiplicidade e alteridade. In: Arruda A, organizador. Representando a alteridade. Petrópolis: Vozes; 1988. p. 129-47.
Família e doença mental: a difícil convivência com a diferença 